\title{
Pedro Kilkerry entre arquivos e arcontes
}

Resumo: A poesia de Pedro Kilkerry (1885-1917) é complexa e singular, também complexo é circunscrever o arquivo Pedro Kilkerry na historiografia literária brasileira. Este artigo objetiva apreender e refletir sobre o lugar ocupado pelo poeta nos arquivos oficiais da literatura brasileira. A partir da noção de arquivo de Jacques Derrida (2001), discutem-se os processos de arquivamento aos quais a obra do poeta foi submetida após sua morte. Tomados pelo desejo, pela paixão de recuperar a origem, pergunta-se sobre os traços que singularizam os processos de desarquivamento e arquivamento realizados em sua obra ou mesmo como avaliar o papel e as impressões inscritas pelos arcontes no arquivo do poeta. Ao responder questões como essas, passa-se a interrogar o "mal de arquivo".

Palavras-chave: Pedro Kilkerry, Simbolismo, arquivo, "mal de arquivo", poesia

Abstract: The poetry of Pedro Kilkerry (1885-1917) is complex and unique, it is also complex to circumscribe the Pedro Kilkerry's archive in the Brazilian literary historiography. This article aims to apprehend and reflect on the place occupied by the poet in the official archives of Brazilian literature. Based on Jacques Derrida's (2001) notion of archiving, the archiving processes to which the poet's work was submitted after his death are discussed. Seized by the desire, by the passion to recover the origin, one asks about the traits that distinguish the processes of unarchiving and archiving carried out in his work or even how to evaluate the role and impressions inscribed by the archons in the poet's archive. When answering questions like these, the "archive fever" is questioned.

Keywords: Pedro Kilkerry, Symbolism, archive, "archive fever", poetry 


\section{Introdução}

A estranha e singular poesia de Pedro Kilkerry (1885-1917) habita oficialmente, desde meados do século XX, os arquivos da literatura brasileira como representante de uma categoria não menos obscura na historiografia literária, o Simbolismo. A leitura de seus poemas, cerca de cem anos após sua morte, no entanto, perturba por sua complexidade e por se destacar dos traços da poesia simbolista praticada no Brasil na entrada do século XX. Trata-se de uma lírica obscura, hermética, rica em imagens, vibrações sonoras e transgressões sintáticas, por meio das quais o poeta expressa sua experiência de mundo não menos obscura e estranha, além de aparentemente contraditória, pois revela, de um lado, a sensibilidade de um corpo sensorial capaz de perceber atenta e singularmente os objetos e seres que se manifestam concretamente na realidade, e de outro, a percepção inusitada e, às vezes, delirante do drama que move a relação entre sujeito e mundo.

Para construirmos um percurso de leitura crítico, que nos permita alcançar alguma compreensão a respeito da recepção e da projeção da obra de Kilkerry no âmbito de nossa literatura, não podemos nos esquecer da constituição singular de seu corpus, ou seja, não podemos perder de vista o arquivo Pedro Kilkerry. Seus escritos, enquanto documentos legítimos a serem vasculhados pelo pesquisador-arquivista, só se realizam no âmbito de um projeto maior, de recuperação e reorganização do arquivo literário. Sua obra, esparsa, só ganhou publicação em livro após sua morte e seu nome só passou a constar, de fato, nos arquivos oficiais de nossa história literária a partir da década de 1970, com a publicação de Re-visão de Kilkerry, fruto do esforço de pesquisa de Augusto de Campos (1970), responsável por um estudo crítico e pelo levantamento da obra completa de Kilkerry e de sua fortuna crítica e biográfica.

Considerando que a obra poética de Pedro Kilkerry foi reunida e organizada a partir da perspectiva singular de Augusto de Campos, propomos investigar como se deu o processo de configuração do arquivo que constitui a obra do poeta e verificar quais princípios manifestam-se na recuperação e na organização de seus escritos. Acreditamos que as reflexões e proposições realizadas por Jacques Derrida (2001) em Mal de Arquivo: Uma impressão freudiana, constituem o fundamento teórico mais adequado para sustentar tal investigação. Desse modo, ponderamos, inicialmente, realizar uma breve exposição sobre a conferência de Derrida, a fim de apresentar algumas noções fundamentais para que, em seguida, possamos investigar os procedimentos e princípios adotados na organização de sua obra poética a partir da lógica arquival.

\section{Mal de arquivo e arquivo mal}

No preâmbulo de sua conferência proferida em 05 de junho de 1994, no Museu Freud, em Londres, na qual investiga os meandros do arquivamento a que foram submetidos o pensamento produzido por Sigmund Freud e a história da Psicanálise, Jacques Derrida (idem: 43-44) apresenta o seguinte comentário a respeito do conceito de arquivo: 
Ora, quanto ao arquivo, Freud jamais conseguiu formar um conceito digno deste nome. Nós também não. Não temos conceito, apenas uma impressão, uma série de impressões associadas a uma palavra. Oponho aqui o rigor do conceito à vaga ou mesmo franca imprecisão, à relativa indeterminação de uma tal noção. "Arquivo" é somente uma noção, uma impressão associada a uma palavra e para a qual Freud e nós não temos nenhum conceito.

Nessa passagem, o filósofo revela a perspectiva desconstrucionista que sustenta seu pensamento, alertando para o caráter autoritário que se manifesta na formulação e no emprego de qualquer terminologia conceitual, pois entende que a relação entre um conceito e o termo que o nomeia é inevitavelmente contaminada pela homegeneidade e univocidade que caracterizam todo e qualquer discurso científico. A esse fechamento, o filósofo prefere a imprecisão e a indeterminação das noções, por meio das quais acredita ser possível produzir um pensamento heterogêneo, incompleto e aberto a questionamentos.

Como ponto de partida para a desconstrução e reelaboração do conceito de arquivo, o pensador propõe uma investigação sobre a origem etimológica do termo, colocando em destaque sua raiz: o vocábulo grego arkhê. Segundo o filosófo, arkhê conjuga dois princípios a partir de uma dupla designação: começo - físico, histórico e ontológico, "princípio da natureza ou da história, ali onde as coisas começam" (Derrida 2001: 11) e comando - princípio da lei, a partir do qual se exerce a autoridade e a ordem social, um princípio nomológico, já que consiste "nesse lugar a partir do qual a ordem é dada" (idem: 14). O pensador sugere que o arkhê do comando predomina sobre o da memória na constituição de um arquivo, ao contrário do que, à primeira vista, poderíamos acreditar.

Ao desconstruir o conceito do arquivo, Derrida (idem: 11) verifica uma tensão que se manifesta na violenta sobreposição do princípio do comando ao princípio do começo, colocando em crise a associação corrente entre arquivo e memória: o começo não pode ser revisitado, dada a impossibilidade de se recuperar integralmente um evento do passado, no entanto o comando quer, a todo custo, repeti-lo, eternizá-lo, imortalizá-lo, tornando-o, porém, finito.

Avançando em sua investigação sobre a origem etimológica do vocábulo arquivo, Derrida (idem: 14) lembra também que o termo latino archium (ou arquivum) origina-se do grego arkheîon, que designava

inicialmente uma casa, um domicílio, um endereço, a residência dos magistrados superiores, os arcontes, aqueles que comandavam. Aos cidadãos que detinham e assim denotavam o poder político reconhecia-se o direito de fazer ou de representar a lei. Levada em conta sua autoridade publicamente reconhecida, era em seu lar, nesse lugar que era a casa deles (casa particular, casa de família ou casa funcional) que se depositavam então os documentos oficiais. Os arcontes foram os seus primeiros guardiões. Não eram responsáveis apenas pela 
segurança física do depósito e do suporte. Cabiam-lhes também o direito e a competência hermenêuticos. (idem: 12-13)

Dessa forma, o filósofo evidencia que o arkhê do comando prevalece sobre o do começo na memória do conceito "arquivo", já que sua origem etimológica aponta para o sentido da casa onde os arcontes - magistrados que desempenham o papel de guardiões dos arquivos - depositavam e organizavam os documentos oficiais, exercendo a força da lei. O poder ou força arcôntica, que confere ao arquivo seu estatuto topológico e nomológico, revela-se, portanto, na exigência de que o arquivo seja "depositado em algum lugar sobre um suporte estável e à disposição de uma autoridade hermenêutica legítima" (idem: 13). De acordo com o filósofo, entretanto, o poder arcôntico não é apenas topo-nomológico, pois desempenha também funções de classificação, identificação e unificação, exercendo, portanto, um poder de consignação, ou seja, poder de "consignar reunindo os signos" (idem: 14), que se sobrepõe ao princípio do começo, a partir do qual, aparentemente, deveria se sustentar toda e qualquer tentativa de se preservar a memória.

Qualquer questionamento acerca das leis mediante as quais se institui o poder arcôntico de um arquivo, qualquer segredo ou heterogeneidade que desestabilizem sua força de consignação, podem resultar em "graves consequências, tanto para uma teoria do arquivo, como para sua realização institucional" (idem: 14). Para desestabilizar a autoridade arcôntica e fissurar o poder de consignação que atua sobre qualquer processo de arquivamento, o filósofo propõe a desconstrução da história dos limites que as leis impõem à ciência e ao conceito de arquivo.

Desestabilizar a ordem constitui uma das metas do método desconstrucionista de Derrida no que diz respeito à noção de arquivo. Ainda que essas reflexões críticas tenham como alvo o arquivo da Psicanálise (ou da história da Psicanálise) e suas relações com Freud, elas acabam por redimensionar todo e qualquer fenômeno que manifeste a dinâmica da memória (e do esquecimento). Trata-se de revelar os mecanismos que se instauram na produção de qualquer conhecimento científico, em especial nas humanidades, mediante a cristalização dos conceitos, imposição de métodos, determinação de regras e valores que conduzem os arquivamentos.

Há, no entanto, outras forças que se conjugam aos modos de arquivamento, em especial uma presença inevitável que se instaura no arquivo desde sua origem: uma pulsão de morte que, assim como no aparelho psíquico, promove a destruição por meio do apagamento dos registros e da memória.

Esta pulsão, portanto, parece não apenas anárquica, anarcôntica (não nos esqueçamos que a pulsão de morte, por mais originária que seja, não é um princípio, como o são o princípio do prazer e o princípio de realidade): a pulsão de morte é, acima de tudo, anarquívica, poderíamos dizer, arquiviolítica. Sempre foi, por vocação, silenciosa, destruidora do arquivo. (idem: 21; grifo do autor) 
Força destrutiva, instauradora do fim, a pulsão arquiviolítica promove o "mal de arquivo", essa espécie de perturbação que acomete todo processo de arquivamento. Por extensão, e num processo de inversão dos termos que constituem a expressão, Derrida destaca também a emergência dos "arquivos do mal" (Derrida 2001), resultantes de uma série de esforços empreendidos pelo arquivamento oficial para suprimir, recalcar, dissimular eventos que possam ameaçar o princípio da autoridade arcôntica. 0 "mal de arquivo", todavia, assim como qualquer noção que resulte de um esforço de desconstrução dos conceitos, apresenta dupla face e pode também se referir ao desejo que move o arquivista.

"Estamos com mal de arquivo (en mal d'archive). Escutando o idioma francês e nele, o atributo 'en mal de', estar com mal de arquivo, pode significar outra coisa que não sofrer de um mal, de uma perturbação [...]. É arder de paixão” (Derrida 2001: 118). Essa passagem reflete uma abertura promovida pelo filósofo em seu processo reflexivo: a possibilidade de uma promessa que, arquivioliticamente, permita fissurar o arquivo, destituindo ou ao menos questionando a origem e o propósito das supressões, dissimulações, modulações e outras arbitrariedades cometidas em nome do arkhê do comando (força da lei) no processo de arquivamento original. Para se instituir a promessa como uma meta no processo de arquivamento, deve-se pôr em questão a chegada do futuro:

a questão do arquivo não é, repetimos, uma questão do passado. Não se trata de um conceito do qual nós disporíamos ou não disporíamos já sobre o tema do passado, um conceito arquivável de arquivo. Trata-se do futuro, a própria questão do futuro, a questão de uma resposta, de uma promessa e de uma responsabilidade para amanhã. (idem: 50)

Tendo em vista o "por-vir", ou seja, a abertura do processo de arquivamento para o futuro, ao acesso irrestrito para novas reorganizações, interpretações e releituras dos materiais arquivados, esse novo arquivista pode empreender, em seu ofício, a promessa sugerida pelo filósofo. Forças arquiviolíticas devem mover esse novo arquivista, espécie de anarconte, responsável, a um só tempo, por promover o desarquivamento do passado, consciente das deformações realizadas pelo arquivo oficial, e abrir no arquivo portas para o futuro: o "arquivo, se queremos saber o que isto teria querido dizer, nós só o saberemos num tempo por vir" (idem: 51). Em suma, o arquivo não pode ser compreendido apenas como uma urna que guarda o passado, mas implica uma força de projeção para o futuro. A meta do arquivo e do arquivamento associa-se não só ao resgate, à conservação da memória, mas também à atenção dirigida ao "por-vir", sem perder de vista o autoritarismo e a arbitrariedade deformadora dos arquivos oficiais, que atuam tanto na esfera coletiva quanto na esfera do sujeito, rasurando o passado. 


\section{As origens do arquivo Pedro Kilkerry}

Em carta escrita em 06 de junho de 1911 ao poeta Arnaldo Damasceno Vieira, que no mesmo ano lançara seu Baladas e Poemas (1911), Pedro Kilkerry abordou ironicamente o êxito das publicações em livro, criticando o caráter publicitário dos processos de edição. O desprezo pelo mercado editorial evidenciava um traço marcante de sua participação nos meios literários: a recusa em publicar seus escritos em livro. Segundo colegas da $2^{a}$ geração de simbolistas baianos, Kilkerry produzia versos de sobra, mas os registrava apenas em sua memória ou os espalhava pelo ambiente lúgubre de seu quarto à Rua do Cabeça, "escritos de modo incompreensível sobre páginas de livros, pedaços de papel, até na pouca madeira do leito mesquinho" (Figueiredo 1985: 237). Entre 1906 e 1916, publicou alguns textos em jornais e revistas da época, em especial nos periódicos simbolistas Nova Cruzada e Os Anais. A divulgação póstuma de sua obra - composta por poemas líricos, satíricos, crônicas, textos críticos e cartas - só foi possível em função do esforço de amigos e pesquisadores que se dedicaram a recuperar alguns manuscritos e os poucos textos publicados em vida pelo poeta.

A iniciativa de reunir parte da produção lírica do autor em livro deve-se a Jackson de Figueiredo (1921), que quatro anos após a morte do poeta publicou Humilhados e luminosos, obra em que apresenta o perfil biográfico de escritores obscuros. No segundo capítulo do livro, Figueiredo (1921) apresenta, em forma de ensaio, a biografia do autor, ao longo da qual cita e comenta 15 poemas e fragmentos de prosa escritos por Kilkerry.

Em 1931, Carlos Chiacchio publicou no jornal baiano $A$ tarde uma série de artigos sobre o poeta, na qual realizou um perfil biográfico do autor e divulgou alguns de seus textos inéditos. ${ }^{1}$ Figueiredo e Chiacchio foram os primeiros arcontes da obra poética de Pedro Kilkerry: à revelia da aversão do poeta ao mercado editorial, lançaram-se ao difícil desafio de desarquivar e organizar os textos por ele publicados em revistas literárias e jornais nas décadas de 1900 e 1910, recorrendo também a familiares do poeta e, por um processo de anamnese, às lembranças dos versos declamados pelo poeta nos corredores da Faculdade de Direito da Bahia ou nas reuniões do grupo de poetas simbolistas que se articulavam em torno das revistas Nova Cruzada e Os Anais.

Apesar dos esforços de Figueiredo (1921) e Chiacchio (1985), a poesia de Kilkerry permaneceu na obscuridade até 1952, ano em que Andrade Muricy - arconte maior dos arquivos do Simbolismo brasileiro - publicou a primeira edição de seu Panorama do Movimento Simbolista Brasileiro, na qual incluiu 13 textos de autoria de Kilkerry e uma breve apresentação de sua obra, na qual destaca o poeta como a "figura mais singular do movimento simbolista baiano", situando-o na "primeira plana do Simbolismo" (Muricy 1987: 899-901). Tal feito, é importante ressaltar, só foi possível em virtude da pulsão arquiviolítica que moveu Muricy tanto em seu processo de desarquivamento da produção simbolista brasileira quanto na organização de sua obra. Em seu relato sobre o histórico da pesquisa, Muricy (ibidem) destaca as dificuldades e as escolhas que marcaram o seu trabalho, desenvolvido à margem das normas e das restrições impostas pelo princípio 
arcôntico que dominava os arquivos oficiais da literatura brasileira na primeira década do século XX. Indicado por Manuel Bandeira para organizar uma antologia de poetas brasileiros simbolistas que faria parte de uma coleção planejada pelo Ministério da Educação, coleção que já contava com dois volumes organizados por Bandeira - Antologia dos poetas brasileiros da fase romântica (1937) e Antologia dos poetas brasileiros da fase parnasiana (1938) -, o pesquisador aceitou a proposta, mas não se submeteu às regras impostas para o seu trabalho, insurgindo-se contra a metodologia sugerida para a escoIha dos poetas que deveriam figurar na obra:

Era-me imposto, porém, reunir num só tomo os "simbolistas" e os "pré-modernistas" ou poetas da transição para o modernismo. Os simbolistas significativos, afirmava-se, não seriam em número suficiente para formar um conjunto comparável, em qualidade e interesse representativo, ao dos autores já incluídos naquelas antologias citadas.

Um primeiro exame conduziu-me à evidência da arbitrariedade e à injustiça daquele plano. (idem: 13-14)

Frente à quantidade de documentos recolhidos durante sua pesquisa e à evidência supreendente da expressiva quantidade de poetas que, de alguma forma, sintonizaram-se com a estética simbolista, o pesquisador abandonou a ideia de uma antologia que, a rigor, deveria se restringir a cerca de 20 poetas, substituindo-a pela proposta de um panorama, que lhe permitiria abarcar a diversidade dessa produção, incluindo uma série de autores obscurecidos e suprimidos pelos arquivos oficiais. Sua escolha, entretanto, não passou despercebida pelo arcontes que determinavam as regras de seleção e arquivamento da produção literária, em especial alguns autores responsáveis por organizar outras antologias simbolistas, os quais não pouparam críticas aos critérios de seleção empreendidos na realização do Panorama. No prefácio à segunda edição (1973) e na introdução reformulada para a terceira e última edição da obra (1987), Muricy inseriu comentários a respeito dessas críticas. Dessa introdução, uma passagem especial merece ser transcrita em virtude da clareza e perspicácia demonstradas pelo pesquisador acerca de seu processo de arquivamento e do caráter arbitrário e autoritário daqueles que detinham o poder dos arquivos oficiais no período:

O esforço empreendido durante anos e anos, não para a tentativa ingrata de apresentar "salvados" do tão celebrado "fracasso" do movimento simbolista no Brasil, mas para documentar a sua penetração, tanto em extensão como em profundidade, não foi baldado. $O$ relativo êxito dessa prospecção, dados o geral desleixo e mesmo a inconsciência de familiares dos autores e a miséria das bibliotecas públicas, foi geralmente tomado em consideração. Vários dos meus informantes nem mesmo chegaram a ver a obra publicada: faleceram sem essa ventura. Por outro lado, muitos documentos biográficos e iconográficos retornaram a seus depositários, e estão, alguns deles, presentemente, em lugar ignorado. Essa circunstância não se 
refere somente a autores de segunda ou mais humilde plana, porém mesmo a autores muito principais. Assim advertido, leituras posteriores vieram trazer-me testemunhos expressivos, justificativos de vários ângulos, do critério adotado. (Muricy 1987: 19)

De uma só vez, o autor assume sua posição como novo arconte do Simbolismo brasileiro e apresenta um relato que ilustra com clareza a dinâmica constituinte dos arquivos oficiais da literatura brasileira. Como propõe Derrida (2001), Muricy deixa-se contaminar por uma força anarquívica que lhe permite colocar em crise a homogeneização, a supressão e o apagamento da memória provocados pela atuação do arkhê do comando na configuração de um cânone simbolista a ser violentamente incluído no arquivo da Literatura Brasileira. Além disso, ao comentar a indiferença de familiares de autores e de bibliotecas públicas quanto à preservação dos documentos originais, o pesquisador ilustra com exatidão a noção de "mal de arquivo" tal como proposta por Derrida, resultante da pulsão de morte que se instala em todo e qualquer arquivo, levando à sua destruição. O Panorama do movimento simbolista brasileiro avulta, dessa forma, como um arquivo do mal, composto, em grande parte, de autores e obras que, condenados ao esquecimento, assumem a posição de testemunhos sobre os dispositivos que colocam em risco a memória literária brasileira. A abertura realizada por Muricy no arquivo do Simbolismo brasileiro foi determinante para a projeção da poesia de Pedro Kilkerry a um público mais amplo e sensível às novidades. Por meio do Panorama do Movimento da Poesia Simbolista Brasileira, por exemplo, os escritores da Poesia Concreta conheceram sua produção lírica e logo perceberam seu valor. De 1962 a 1967, cinco ensaios sobre a poesia de Kilkerry foram publicados por Augusto de Campos em diferentes suplementos literários (O Estado de S. Paulo, Estado de Minas, Diário de notícias de Salvador e Correio da Manhã): "Non Multa Sed Multum" (1962); "O revolucionário Kilkerry" (1962); "Re-visão de Kilkerry” (1965); e "Pedro Kilkerry: a harpa esquisita” (1967). Em 1970, esses arquivos foram reorganizados e lançados como a primeira parte do livro Re-visão de Kilkerry, no qual Campos (1970) apresentava, além de seu ensaio sobre Kilkerry, uma reunião de todos os textos do poeta (poemas e escritos em prosa), acompanhada de perfis biográficos, ensaios de autores diversos e uma série de documentos associadas à vida e a obra do escritor baiano. Em 1985, ano que marcou o centenário de nascimento de Kilkerry, Campos publicou a segunda edição do livro (ReVisão de Kilkerry), ampliada.

Pouco mais de cem anos após a morte de Kilkerry, a pesquisa realizada por Augusto de Campos entre as décadas de 1960 e 1980 permanece, sem dúvida, como o trabalho mais significativo a respeito da recuperação e da divulgação da obra de Pedro Kilkerry. ReVisão de Kilkerry consiste, até hoje, no arquivo mais completo, constituído por um processo de arquivamento e desarquivamento meticuloso e crítico. Além disso, a publicação marcou também a consolidação do arquivo Pedro Kilkerry e sua inserção nos arquivos oficiais da literatura. Nesse sentido, para que se possa realizar um exame crítico da obra do poeta, não se devem desconsiderar os procedimentos empregados por Augusto de 
Campos em seu arquivamento. Isso porque "a estrutura técnica do arquivo arquivante determina também a estrutura do conteúdo arquivável em seu próprio surgimento e em sua relação com o futuro. O arquivamento tanto produz quanto registra o evento" (Derrida 2001: 28-29).

O arquivo não é, portanto, mero local de estocagem dos registros que constituem seu conteúdo arquivável. A estrutura do arquivo condiciona os próprios registros, uma vez que os modos de consignação que participam de um arquivamento condicionam os registros aos valores de classificação, identificação e homogeneização que regem o poder arcôntico e determinam os modos de leitura e interpretação de tais registros. Se o arquivamento, ao mesmo tempo, registra e produz um evento, devemos nos aproximar da poesia de Pedro Kilkerry reunida em ReVisão de Kilkerry, levando em consideração que ela não foi selecionada e organizada, enquanto arquivo, para atender às intenções de KiIkerry, mas é fruto de escolhas e critérios adotados por Augusto de Campos (1970; 1985) em seu arquivamento. Tendo isso em vista, devemos verificar de que forma a ReVisão foi concebida e quais critérios foram adotados por Augusto de Campos para apresentar o poeta e sua obra ao público.

Em sua primeira edição, o livro foi organizado em duas partes ("Augusto de Campos - Re-visão de Kilkerry" e "Pedro Kilkerry - Harpa Esquisita”) e mais dois apêndices. A primeira parte, "Re-visão de Kilkerry", consiste de um ensaio de autoria de Augusto de Campos dividido em seis seções ("Non multa sed multum", "Em busca dos textos perdidos", "A harpa esquisita de Pedro Kilkerry”, "Análise estrutural de um poema”, "As palavras-chave de Kilkerry" e "Olhos novos para o novo"), acrescidas de mais duas seções: "Nota sobre esta edição" e "Síntese biográfica de Kilkerry".

A segunda parte do livro, "Pedro Kilkerry - Harpa esquisita", reúne todos os textos escritos por Kilkerry recuperados até aquele momento - poemas em versos, prosa poética, crônicas - organizados em sete seções: "Sonetos" (12 sonetos), "Recriações" (três poemas traduzidos pelo autor), "Poemas" (onze poemas de formas diversas), "Sátiras" (três fragmentos satíricos), "Manuscritos" (seis poemas extraídos dos únicos manuscritos do poeta recuperados), "Notas trêmulas e outras" (reunião de 12 textos em prosa de Kilkerry, dentre os quais se destacam as oito crônicas que compõem a série "Quotidianas - Kodaks") e "Prosa esparsa" (uma conferência, duas cartas e três artigos de autoria de Kilkerry).

Além dessas duas partes - "Re-visão de Kilkerry"e "Harpa esquisita" - Augusto de Campos inseriu dois apêndices finais ao livro: o primeiro, "Dois perfis de Kilkerry", inclui dois perfis biográficos do poeta, escritos por Jackson de Figueiredo e Carlos Chiaccio; o segundo, "Subsídios biográficos", contém cópias de documentos (certidão de nascimento, matrícula na Faculdade de Direito da Bahia e cartas, além do título de nomeação ao cargo que Kilkerry ocupou como advogado nos últimos anos de sua vida), notas sobre o falecimento do autor em publicações da época e dois breves ensaios a seu respeito, escritos por Sílvio de Vilar e Berbert de Castro. Ao longo do livro, há também uma série de 
páginas com reproduções fotográficas e fac-símiles de manuscritos do autor.

Na segunda edição da obra, publicada em 1985, Campos preservou a estrutura em duas partes, mas realizou modificações significativas, como a incorporação de novos materiais e a reconfiguração da distribuição dos textos de Kilkerry no livro. Uma "Breve reintrodução" abre a segunda edição, na qual Campos apresenta as novidades, destacando o trabalho de Erthos Albino de Souza, outro arconte da obra de Pedro Kilkerry movido pelo "mal de arquivo":

Erthos Albino de Souza [...] conseguiu, por fim, ter acesso a uma coleção completa da revista A Nova Cruzada, o que propiciou a identificação da publicação original de várias obras de Kilkerry. Em face desses novos elementos, foi possível estabelecer uma cronologia parcial, que vem complementar a coletânea dos seus textos, distribuídos neste livro segundo critérios estilísticos, mas agora reorganizados cronologicamente. (Campos 1985: 15)

Graças a Erthos Albino de Souza, também foi possível ampliar a obra com vários outros textos, a saber: dois sonetos inéditos ("Mare Vitae" e "Vinho"); "Navis serenissima", prosa poética do autor incluída na seção "Notas trêmulas e outras"; dois ensaios críticos do poeta sobre Xavier Marques, um artigo sobre Cécile Périn e uma conferência sobre Eça de Queirós, incluídos na seção "Prosa Esparsa"; três cartas e dois cartões escritos por Kilkerry para Xavier Marques; um ensaio de Carlos Chiacchio sobre o poeta e mais uma série de documentos relacionados ao autor, incluídos no apêndice 2 do livro ("Subsídios biográficos").

Além dessas inserções, a reedição da obra ganhou também dois novos apêndices. No apêndice 3, foram incluídas oito crônicas publicadas anonimamente na revista Via Láctea entre 1911 e 1912 e atribuídas por Erthos Albino de Souza a Kilkerry. No apêndice 4, consta um breve texto ("Kilkerry, Mallarmé e o mau leitor") no qual Augusto de Campos responde com ferocidade a críticas lançadas por Heitor Martins à primeira edição de ReVisão. Fecham o livro uma "Biografia sobre Pedro Kilkerry", organizada por Erthos Albino de Souza, e um índice de ilustrações.

Além dos novos textos, algumas mudanças salientam-se na nova edição, a começar pelo título da obra, que perdeu o hífen presente na primeira edição ("Re-visão"), e ganhou uma nova inicial maiúscula ("ReVisão"), configuração que ressalta com mais força a ambiguidade do projeto, ao mesmo tempo, revisão e visão: exercício de retorno crítico e meticuloso à obra de um autor desconhecido a partir do ponto de vista de Augusto de Campos. Outra mudança diz respeito à distribuição dos textos do poeta na segunda parte do livro. Em geral, a divisão realizada na edição original foi preservada, levando-se em consideração a combinação de vários critérios. Em "Sonetos" e "Poemas", os poemas foram divididos a partir de um critério formal (tipo de composição poética a que pertencem). Em "Sátiras", "Notas trêmulas e outras" (crônicas e textos em prosa poética) e "Prosa esparsa" (textos não-ficcionais), a organização parece obedecer à lógica dos gêneros literários de 
que fazem parte os registros. Outras duas seções reúnem poemas traduzidos por Kilkerry ("Recriações") e seus manuscritos ("Manuscritos"). Em cada seção, a distribuição dos textos não parece seguir nenhum critério aparente, conforme explica o próprio Augusto de Campos (1970: 48):

Dada a inviabilidade de se estabelecer a cronologia completa das obras de Kilkerry, afastou-se, desde logo, a ideia da reunião de suas produções sob critério rígido desta natureza. Pareceu-nos razoável separar a poesia dos textos em prosa (mesmo os poéticos).

Na segunda edição (1985), Campos preservou a mesma estrutura em seções, mas efetuou algumas alterações, tais como a abertura de uma seção independente para abrigar a série de crônicas "Quotidianas - Kodaks” publicadas por Kilkerry no Jornal Moderno em 1913, as quais, na primeira edição, faziam parte da seção "Notas trêmulas e outras". Além disso, a ordem de apresentação dos textos em cada seção foi alterada mediante a adoção do critério cronológico; tal mudança só foi possível graças às informações obtidas por Erthos Albino de Souza. Campos (1985: 68) afirma que a cronologia "oferece importante subsídio tanto para seguir-se a evolução literária do poeta quanto para a fixação, ainda que presuntiva e incerta, da época da produção" de manuscritos e outros textos de origem incerta.

Diante desse breve mapeamento a respeito da estrutura das duas edições da obra, é possível levantar algumas questões: quais são os princípios que regem o arquivo ReVisão de Kilkerry? Quais são os traços que singularizam os processos de desarquivamento e arquivamento realizados por Campos nessa obra? Como avaliar o papel desempenhado por Campos enquanto arconte legítimo do poeta Pedro Kilkerry e de sua obra? Finalmente, qual seria a impressão deixada pelo arconte por Campos em seu arquivo, ou melhor, quais seriam as interferências efetuadas por ele em seu processo de criação do poeta Pedro Kilkerry? Tentaremos responder a essas questões.

Quanto à estrutura do livro, é possível identificar características que sugerem a atuação do arkhê do comando na constituição do arquivo em questão. A nosso ver, essa atuação manifesta-se, por exemplo, na maneira como Campos classifica os textos de Kilkerry em seções, a partir de categorias cristalizadas como as de gênero literário e de modelo de composição, que refletem a reprodução de paradigmas oriundos dos arquivos oficiais da literatura brasileira e se manifestam, em especial, na maneira como os manuais de História da Literatura Brasileira apresentam seus registros. Além disso, ao justificar que a mudança seria uma forma de apresentar para o leitor a "evolução literária" de Kilkerry, Campos sucumbe a uma perspectiva historicista a partir da qual a qualidade de uma produção literária poderia ser medida pelo aperfeiçoamento técnico de um escritor ao longo do tempo. A esses aspectos vem somar-se a ênfase dada pelo arquivista à biografia de Kilkerry no livro. Perfis biográficos, correspondências íntimas e diversos outros documentos (certidões, requerimentos, título de nomeação, notas oficiais, fotografias) formam um 
corpo que parece revelar não só o desejo de conferir ao arquivo o estatuto de verdade histórica, mas também a valorização do biografismo como método de leitura e apreciação crítica de uma obra.

Observadas em conjunto, tais caraterísticas sugerem a reprodução de conceitos e valores que reforçam certos modos de ler e de pensar a literatura de forma padronizada e homogênea, traços indiscutíveis da manifestação do poder de consignação dos arquivos oficiais da literatura brasileira sobre o processo de arquivamento de Campos. O resultado da sobreposição do arkhê do comando sobre o do começo, alerta Derrida (2001), é o recalque da memória e a deformação dos registros do passado em nome das leis que sustentam a autoridade dos arquivos oficiais, condenados sempre ao apagamento e à destruição.

Um olhar mais atento, contudo, permite sublinhar determinados procedimentos e escolhas que, a nosso ver, explicitem o caráter anarquívico de Augusto de Campos, ameacem o princípio do comando e os modos de consignação que the são peculiares e, consequentemente, proporcionem aberturas significativas no processo de arquivamento. Dentre esses procedimentos, destaca-se a incorporação, no livro, de uma série de ensaios críticos oriundos de outros arquivos, os quais instauram, no arquivo, a heterogeneidade e a singularidade, abrindo a possibilidade de participação de perspectivas variadas sobre a produção poética de Kilkerry. Além disso, o (an)arquivista apresenta uma série de observações a respeito do processo de desarquivamento e arquivamento que constituíram o livro, em especial na seção "Em busca dos textos perdidos", na qual relata as dificuldades do percurso de pesquisa, o mau estado de conservação dos periódicos nas bibliotecas públicas, a origem incerta de certos poemas e a ausência de métodos críticos nos arquivamentos de Figueiredo e Chiacchio. Ao realizar essa abordagem, Campos também anarquiviza seu trabalho, revelando aspectos obscuros da pesquisa e liberando a possibilidade de colocá-la em crise.

Outra abertura significativa verificada no arquivo ReVisão de Kilkerry diz respeito à dimensão autoral do arquivamento realizado por Augusto de Campos, ou seja, à maneira como ele imprime sua marca no próprio arquivo. Esse traço anarquívico é realçado por Derrida (2001) ao longo de suas considerações sobre a obra Freud's Moses, judaism terminable and interminable, na qual o historiador de Yosef Hayim Yerushalmi propõe uma revisão da história da psicanálise, levando em consideração os traços de judaísmo impressos no pensamento de Freud. São duras as críticas do filósofo ao historiador, em especial ao papel de "observador neutro" assumido por Yerushalmi, que se coloca numa posição de exterioridade em relação ao seu objeto, uma vez que um historiador deveria se inserir no próprio discurso, assumindo sua posição de "sujeito deste saber histórico" (idem: 71). Entretanto, ao desenvolver sua reflexão sobre a postura do arquivista em relação ao arquivo, o filósofo constata também que uma das qualidades do livro é a presença de uma auctoritas, de um sujeito que se inscreve no próprio arquivo a partir de seu saber: 
Incorporando o saber que se demonstra sobre [o] tema, o arquivo aumenta, cresce, ganha em auctoritas. Mas perde, no mesmo golpe, a autoridade absoluta e metatextual que poderia almejar. Jamais se poderá objetivá-lo sem um resto. 0 arquivista produz arquivo, e é por isso que o arquivo não se fecha jamais. Abre-se a partir do futuro. (Derrida 2001: 88)

Trata-se, portanto, de uma abertura para o futuro promovida pelo gesto do arquivista que, sem se comprometer com a lei da objetividade do discurso científico imposta pelos arquivos oficiais, inscreve-se no próprio arquivo, evitando seu fechamento.

$\mathrm{Na}$ esteira desse pensamento, não se pode negar a manifestação de uma auctoritas no arquivamento de Pedro Kilkerry. Arquivista tomado pelo "mal de arquivo", Augusto de Campos não se submete ao princípio do comando, reorganizando criticamente os registros dos arquivos que lhe antecedem a partir de um saber constituído sobre o objeto em questão e da explicitação de seu ponto de vista, em especial no ensaio em que se lança à investigação e à reinterpretação da poesia de Pedro Kilkerry. A fim de apreendermos as marcas dessa auctoritas no arquivamento de Pedro Kilkerry, propomos um exame das impressões deixadas por Campos em ReVisão de Kilkerry.

\section{Kilkerry: entre o Simbolismo e o paideuma da Poesia Concreta}

Autoritário, convencional, rígido, excludente é o arquivo oficial responsável pela memória de nossa literatura. Sob o rótulo de História da Literatura Brasileira, o princípio arcôntico do comando, em sua sede de classificação, categorização e unificação, submete o acervo literário a modos de consignação tão rígidos, que acabam por suprimir qualquer traço que coloque em perigo sua autoridade. Nesse arquivo oficial, regido pela perspectiva historicista, a heterogeneidade que caracteriza o discurso literário é rasurada e substituída por categorias rígidas e arbitrárias, em nome da estabilidade e da preservação de determinados valores.

Especialmente a partir do século XIX, no entanto, essa dinâmica asfixiante passou a encontrar na prática de determinados escritores e artistas um obstáculo que ameaçou seu pleno funcionamento. Márcio Seligmann-Silva, em sua análise sobre as tendências anarquizadoras da arte contemporânea, esclarece:

O abalo no arquivo central do Esclarecimento levou a uma disseminação dos saberes. [...] Ao invés da fé cega na razão e na sua capacidade de revelar a verdade, surge cada vez mais ao longo da modernidade um outro modo de pensar e de agir que desconfia dos arquivos.

[...] No bojo do romantismo, artistas levantaram-se em revolta contra a ação da norma e sua tendência a reduzir tudo ao(s) arquivo(s) do poder. Artistas se tornam cada vez mais anarquivadores, anarquizadores do arquivo. (Seligmann-Silva 2014:37-38)

No século XX, esse ímpeto anarquívico atravessou com força a literatura e as artes brasileiras, colocando em crise a legitimidade e a autoridade do arquivamento oficial, 
conforme comprovam os sismos provocados por fenômenos como a Poesia Concreta. Idealizadores dessa vanguarda, Décio Pignatari, Haroldo e Augusto de Campos fissuraram os arquivos da literatura brasileira mediante procedimentos radicais, tais como a proposta de uma poesia verbivocovisual e a explosão do verso. Além disso, em sua diversificada e rigorosa produção crítica e teórica, colocaram em crise o primado da perspectiva histórico-sociológica sobre o arquivamento oficial. Quanto ao historicismo, aliás, os poetas concretos foram impiedosos: questionaram o princípio diacrônico como critério de seleção e julgamento de autores, obras e escolas, substituindo-o pelo recorte sincrônico, instaurando a possibilidade de novas articulações entre obras e escritores do nosso passado literário.

Exemplo marcante do impulso anarquívico da Poesia Concreta foi o emprego do princípio do paideuma ${ }^{2}$ - emprestado do poeta norte-americano Ezra Pound - como método alternativo para o desarquivamento do passado literário e para a promoção de novas formas de agrupamento de autores e obras. A rigor, para criar seu paideuma, um autor deveria não só revisitar a história literária, dispondo em crise conceitos e paradigmas, mas também considerar os arquivos extraoficiais como fonte de pesquisa legítima, em busca de afinidades com a sua própria produção. Tal estratégia não só permitiu aos poetas concretos estabelecerem seus próprios precursores, a partir de critérios por eles mesmos escolhidos, mas também resultou em uma extensa reavaliação do cânone literário.

No paideuma da Poesia Concreta, ao lado de nomes que já participavam dos arquivos oficiais - como Stéphane Mallarmé, James Joyce, Ezra Pound, E. E. Cummings, João Cabral de Melo Neto e Oswald de Andrade -, figuravam autores praticamente desconhecidos ou desprezados pelos arcontes da literatura brasileira. Dentre esses, dois casos merecem especial atenção por terem conquistado sua entrada nos arquivos oficiais sob os auspícios da Poesia Concreta: Sousândrade ${ }^{3}$ e Pedro Kilkerry, duas singularidades suprimidas da história literária por não se alinharem aos valores de sua época, resgatadas das cinzas pelo esforço anarquívico de Augusto de Campos.

Acreditamos que qualquer tentativa de se aproximar criticamente da obra de Kilkerry não pode se ater apenas à análise do contexto em que foi escrita, mas deve considerar, em especial, as condições que proporcionaram seu arquivamento e as motivações que mobilizaram seu arquivista no processo. Se é verdade que "a estrutura técnica do arquivo arquivante determina também a estrutura do conteúdo arquivável em seu próprio surgimento e em sua relação com o futuro" (Derrida 2001: 29), então é necessário incorporar à investigação o exame das impressões deixadas por Augusto de Campos ao criar seu arquivo. Cabe a nós buscar tais impressões, uma vez que o "futuro" ao qual se relaciona o "conteúdo arquivável” do arquivo Pedro Kilkerry irrompe neste instante reflexivo.

A breve descrição da organização de ReVisão de Kilkerry já nos permitiu identificar, na configuração desse arquivo, a presença de uma auctoritas que se insurge contra a autoridade dos arcontes da História da Literatura Brasileira. Vimos também que essa auctoritas, assentada na figura anarquívica de Augusto de Campos, associa-se, por sua vez, a um 
projeto mais amplo de arquivamento, à formulação de um paideuma para a Poesia Concreta. Resta, então, examinarmos as operações de interpretação efetuadas em ReVisão de Kilkerry, a fim de apreender as impressões deixadas por Augusto de Campos ao inscrever-se, enquanto (an)arquivista, no arquivo e no conteúdo arquivável da obra. Para tanto, propomos uma breve análise do ensaio crítico apresentado por Campos na primeira parte da obra.

Desde o início do ensaio, o arquivista revela sua apreciação crítica a respeito do arquivo, sugerindo um processo evolutivo a partir do qual o poeta teria se libertado do modelo parnasiano que ainda vigorava no início do século XX rumo a experimentações que antecipariam vertentes do Modernismo. Para sustentar essa hipótese, Campos (1985) oferece dados significativos sobre a biografia de Kilkerry, com base em informações extraídas, principalmente, dos perfis biográficos realizados por Figueiredo (1921) e Chiacchio (1985). Ademais, ao longo do estudo, o arquivista tece rápidas e precisas considerações sobre aspectos linguísticos, a partir de fragmentos de vários poemas, enfatizando procedimentos que singularizariam a lírica de Kilkerry no contexto do Simbolismo brasileiro, com destaque para elementos que configuram o extrato sonoro dos poemas e a complexa sintaxe desorganizadora de seu discurso lírico.

A terminologia que predomina no discurso do arquivista explicita essa perspectiva estruturalista em seu exercício interpretativo. Seu posicionamento evidencia-se, por exemplo, na escolha do título de uma das seções: "Análise estrutural de um poema" (Campos 1985: 46). O levantamento estatístico das palavras-chave que frequentam os poemas é outro aspecto que, a nosso ver, denuncia os vínculos entre seu discurso e a índole classificatória que caracteriza o exercício da crítica estruturalista. Exemplo disso é o apontamento realizado a respeito do hermetismo que caracterizaria a lírica do poeta baiano, sintoma de "um estilo novo" no contexto do Simbolismo baiano, mais distante dos modelos parnasianos:

Há nele uma sensibilidade especial para o domínio das interações entre significante e significado, som e sentido, de que fala Jakobson, nos seus admiráveis estudos sobre linguística e poética, quando demonstra que a poesia é a província da linguagem em que o nexo interno entre som e significado se converte de latente em patente. (Campos 1985: 30)

Comentários dessa ordem são frequentes no discurso do arquivista e colocam em evidência, no plano de arquivamento da obra, a influência marcante de valores e métodos que remetem às correntes formalista e estruturalista aplicados como método de análise crítico interpretativa, influência muito presente no pensamento produzido no âmbito da Poesia Concreta. Não queremos, com isso, desqualificar ou mesmo sugerir um juízo de valor sobre o arquivamento em questão, mas somente constatar, seguindo Derrida (2001), os rastros que deixam transparecer os modos de consignação atuantes no discurso crítico de Augusto de Campos e confirmam a presença inevitável do arkhê do 
comando no arquivo. Tal presença também se expressa nas passagens em que o arconte Augusto de Campos oferece comentários mais demorados sobre determinados poemas. É o caso, por exemplo, da análise de "É o silêncio...", poema de Kilkerry que transcrevemos a seguir:

É o silêncio, é o cigarro e a vela acesa.

Olha-me a estante em cada livro que olha.

E a luz nalgum volume sobre a mesa...

Mas o sangue da luz em cada folha.

Não sei se é mesmo a minha mão que molha

A pena, ou mesmo o instinto que a tem presa.

Penso um presente, num passado. E enfolha

A natureza tua natureza.

Mas é um bulir das cousas... Comovido

Pego da pena, iludo-me que traço

A ilusão de um sentido e outro sentido.

Tão longe vai!

Tão longe se aveluda esse teu passo,

Asa que o ouvido anima...

E a câmara muda. E a sala muda, muda...

Afonamente rufa. A asa da rima

Paira-me no ar. Quedo-me como um Buda

Novo, um fantasma ao som que se aproxima.

Cresce-me a estante como quem sacuda

Um pesadelo de papéis acima...

E abro a janela. Ainda a lua esfia

Últimas notas trêmulas... O dia

Tarde florescerá pela montanha.

E oh! minha amada, o sentimento é cego...

Vês? Colaboram na saudade a aranha,

Patas de um gato e as asas de um morcego.

(Kilkerry apud Campos 1985: 117-118)

Campos abre seus comentários a respeito do poema, alertando para sua origem incerta: a versão presente em ReVisão de Kilkerry seria a mesma publicada na primeira edição do Panorama do Movimento Simbolista Brasileiro e teria sido fornecida a Andrade Muricy por Álvaro Kilkerry, sobrinho do poeta; no entanto, uma versão diferente do texto, 
sob o título "Noturnos", já constava no primeiro arquivamento da obra do poeta, realizado por Jackson Figueiredo (1921). Em seguida, o arquivista insinua a presença de uma "perquirição mallarmaico-pessoana" no texto, associada à figura de um sujeito que, no instante da criação poética, mostra-se "atento, fenomenologicamente, ao 'bulir das coisas"” (Campos 1985: 42-43). Logo após a transcrição do poema, Campos (idem: 43-44) apresenta considerações sobre a "rica textura melopaica" do discurso, construída a partir de expressivas "cadeias aliterativas", paronomásias e rimas, procedimentos que configuram o caminho de "uma supersonoridade a uma infra-sonoridade". No final de sua análise, comenta sobre o caráter fragmentário do texto, que estaria associado a uma "montagem calidoscópica" espécie de procedimento de articulador das imagens (idem: 42).

Se, por um lado, muitas dessas considerações formuladas pelo arquivista enfatizam, mais uma vez, a força de atuação do pensamento formalista e estruturalista sobre a análise do poema, por outro, não se pode negar a presença de apontamentos que parecem deslocar-se do problema da estrutura e da forma significante e apontar para outros aspectos, mediante insights lançados de forma concisa e precisa para o leitor. Tais lampejos revelam-se, por exemplo, no comentário sobre a atenção fenomenológica do sujeito lírico diante do real, ideia que apenas alude a uma outra dimensão do discurso poético na qual se manifesta o problema da subjetividade lírica e das estranhas experiências de alteridade expressas nos textos de Kilkerry.

Nesses breves momentos, o arquivista parece abrir o seu discurso a outras maneiras de se investigar um poema, sem se ater a categorias, conceitos e terminologias que anunciam o princípio arcôntico da lei, do comando, o qual condiciona a leitura e o texto à rigidez de determinados modelos de análise. Essa fissura operada no arquivo, essa mirada em direção ao futuro, condição necessária para que se possa tomar o lugar do arkhê do comando no arquivamento, nos instiga a perceber, na leitura de um poema como "É o silêncio...", camadas inacessíveis a uma análise centrada no engendramento do plano formal de um texto, tais como: a dinâmica de alteridade que move o contato entre sujeito e mundo; a presença incontornável de um corpo aberto às sensações; o espanto diante da face enigmática da experiência; entre outros aspectos muito frequentes na poesia e na prosa poética de Kilkerry.

\section{Considerações finais}

A partir das tensões e das contradições verificadas ao longo deste trabalho a respeito da origem e da configuração do acervo literário de Pedro Kilkerry, faz-se necessário esboçar algumas considerações a fim de se abrirem novos caminhos que permitam apreender os traços que singularizam sua obra e o lugar por ela ocupado na literatura brasileira.

Levando-se em consideração a impossibilidade ontológica de se recuperar integralmente o passado original dos eventos e dos monumentos literários, procuramos apoio em Jacques Derrida (2001) como alternativa para estabelecermos um contato renovado com a poesia de Kilkerry, sem o fantasma da autoridade que sustenta a historiografia literária. 
As desconstruções operadas pelo filósofo, mais do que se prestarem como alternativa a uma visão historicista, iluminaram a complexidade da lírica de Kilkerry, deixando transparecer sua natureza de arquivo configurado à revelia do próprio escritor.

Tendo em vista que o acervo do poeta, enquanto arquivo, sofreu uma série de modificações até alcançar sua configuração mais completa na segunda e última edição de ReVisão de Kilkerry, assumimos o "mal de arquivo", ou seja, esse desejo compulsivo que direciona o sujeito para o passado, na vã tentativa de recuperar a origem. Nesse percurso, Jackson Figueiredo (1921) e Carlos Chiacchio (1985) despontaram como os primeiros arcontes da poesia de Kilkerry, responsáveis por resgatá-la das cinzas de nosso passado literário, movidos pela vontade de preservação e projeção de seus arquivos para o futuro.

Já a análise do arquivamento a que se submeteu a obra do poeta na constituição do Panorama do Movimento Simbolista Brasileiro, fez emergir as tensas relações oriundas da atuação do arkhê do comando - autoritário, arbitrário e classificatório - sobre o arquivo oficial da História da Literatura Brasileira. Verificou-se que Andrade Muricy (1952), arconte maior da poesia simbolista brasileira, imbuído da missão de preservar nossa produção simbolista para as gerações futuras, não se sujeitou à violência arquival do arquivo oficial, deixando forte impressão na literatura brasileira e na constituição do arquivo de Kilkerry. O arquivamento realizado por Augusto de Campos (1970, 1985), por sua vez, exigiu maior esforço de análise.

Campos assume, por um lado, a pulsão anarquívica como estratégia de atuação no arquivo da literatura brasileira e põe em crise as normas e os valores que sustentam tal arquivo, visto que esse arconte também ocupa lugar central nos arquivos da Poesia Concreta, da qual é um dos idealizadores e principais expoentes. Essa dinâmica atravessa a configuração do arquivo de Pedro Kilkerry e, inevitavelmente, o contamina, pois sua obra poética, enquanto conteúdo arquivável, confunde-se com o próprio arquivo arquivante. Por isso, entendemos que a poesia de Kilkerry e sua própria figura de autor na literatura brasileira sofre deslocamentos contínuos entre a posição que lhe foi reservada no arquivo original do Simbolismo e sua participação no paideuma da Poesia Concreta.

O exame do ensaio de Augusto de Campos, por outro lado, evidenciou a auctoritas que sustenta, anarquivicamente, seu modo de arquivamento e desarquivamento, fissurando o arquivo Pedro Kilkerry e lançando-o ao "por-vir". Essa auctoritas associa-se à perspectiva assumida pelo arquivista perante seu arquivo: não esconde o seu papel e sua responsabilidade enquanto arconte do arquivo Kilkerry, tampouco assume a falsa neutralidade que caracteriza o discurso acadêmico, pelo contrário, explicita seu ponto de vista e não poupa esforços para acentuar as proximidades entre a lírica de Kilkerry e o paideuma da Poesia Concreta.

Finalmente, acreditamos que os traços que caracterizaram o arquivamento de Pedro Kilkerry no decorrer dos 1900 e, em especial, as impressões deixadas por Augusto de Campos no arquivo do poeta simbolista confirmam a posição indeterminada que sua obra assumiu desde a origem e manifestam sua singularidade. A publicação de Campos 

da literatura brasileira, a poesia de Pedro Kilkerry permanece como testemunho inclassificável e aberto a novas leituras e apreciações.

\section{NOTAS}

* Carlos Eduardo Siqueira Ferreira de Souza: Doutorando em Literatura e Crítica Literária pelo Programa de Estudos Pós-Graduados em Literatura e Crítica Literária da Pontifícia Universidade Católica de São Paulo, possui Mestrado em Literatura e Crítica Literária (2008) pelo mesmo programa. Atualmente é professor da Pontifícia Universidade Católica de São Paulo. É autor do livro A lírica Fragmentária de Ana Cristina Cesar: Autobiografismo e montagem (EDUC, 2010) e dos artigos "O retorno do sujeito lírico: desapossamento, dispersão e alteridade" (Revista FronteiraZ, 2014) e "A vertigem das sensações em "É o silêncio...", de Pedro Kilkerry" (Revista da Anpoll, 2019).

** Maria Aparecida Junqueira: Doutora em Comunicação e Semiótica pela Pontifícia Universidade Católica de São Paulo. Professora do Programa de Estudos Pós-Graduados em Literatura e Crítica Literária da PUC-SP. Líder do Grupo de Pesquisa Estudos de Poética: Interconexões Diacrônico-Sincrônicas na Poesia Brasileira e Portuguesa (PUC-SP/CNPq). Membro do GT Teoria do Texto Poético da ANPOLL. Autora do livro: Samir Curi Meserani: a escrita como ofício (EDUC, 2017). Co-organizadora dos livros: Poesia: entre lugares (Dobradura Editorial, 2016); Livro-Objeto: pluralidade, potência (PUC-SP, BT Acadêmica, 2019). Co-editora do livro Constelações urbanas: territorialidades, fluxos, manifestações estético-políticas (EDUC, 2018).

${ }^{1} \mathrm{O}$ ensaio de Chiacchio foi republicado, com alterações, em capítulos distribuídos em seis números da Revista da Academia de Letras da Bahia, de 1931 a 1933.

${ }^{2}$ No ensaio que abre a edição brasileira de $A b c$ da literatura, de Ezra Pound, Augusto de Campos apresenta uma definição para o termo paideuma: "ordenação do conhecimento de modo que o próximo homem (ou geração) possa achar, o mais rapidamente possível, a parte viva dele e gastar um mínimo de tempo com itens obsoletos" (Campos 2001: 11). Emprestado do antropólogo e etnólogo Leo Frobenius, o termo é usado por Pound para propor uma nova forma de organizar o arcabouço da poesia universal, mediante uma perspectiva singular que permite organizar novos conjuntos (em oposição a escolas ou movimentos) de autores e obras, a partir de traços e procedimentos determinados pelo próprio autor. O conceito é disposto no apêndice incluído na edição brasileira de $A b c$ da literatura, no qual Campos (idem: 161-218) apresenta uma "Mini-antologia do paideuma poundiano", com traduções de poemas de uma série de autores comentados e destacados por Pound em seu livro. 
${ }^{3}$ A obra do poeta maranhense Sousândrade (1833-1902) foi resgatada da obscuridade por Augusto e Haroldo de Campos em 1964, com a publicação de Re-visão de Sousândrade.

\section{BIBLIOGRAFIA}

Campos, Augusto de (1970), Re-visão de Kilkerry, São Paulo, Fundo Estadual de Cultura.

-- (1985), ReVisão de Kilkerry, São Paulo, Brasiliense.

-- (2001), "As antenas de Ezra Pound", in Abc da literatura, tradução de Augusto de Campos e José Paulo Paes, São Paulo, Cultrix, 09-14.

Chiaccio, Carlos (1985), "Pedro Kilkerry”, in ReVisão de Kilkerry, São Paulo, Brasiliense, 259288.

Derrida, Jacques (2001), Mal de arquivo. Uma impressão freudiana, tradução de Claudia de Moraes Rego, Rio de Janeiro, Relume Dumará.

Figueiredo, Jackson de (1921), Humilhados e luminosos, Rio de Janeiro - Porto, Annuario de Brasil - Renascença Portuguesa.

Kilkerry, Pedro (1985), “Carta a Arnaldo Damasceno Vieira”, in ReVisão de Kilkerry, São Paulo, Brasiliense, 197-201.

Muricy, Andrade (1987), Panorama do Movimento Simbolista Brasileiro, volume 1, São Paulo, Perspectiva.

Seligmann-Silva, Márcio (2014), "Sobre o anarquivamento. Um encadeamento a partir de Walter Benjamin”, in Poiésis, n. 24, 35-58. 